\title{
EDITORIAL
}

\section{Neuropathic Pain: The Scope of the Problem}

Giorgio Cruccu - Andrea Truini - on behalf of the Neuropathic Pain Special Interest Group of the Italian Society of Neurology (Italian NeuPSIG)

Received: October 12, 2017

(c) The Author(s) 2017. This article is an open access publication

Many investigators have tried to establish the prevalence of neuropathic pain in the general population; however, the estimates vary greatly (from $0.9 \%$ to $17.9 \%$ ) [1] according to the method used. In particular, the estimates are low when neurological diseases that cause pain are assessed, and high when typical neuropathic pain symptoms are considered. Surveys conducted in the European general population reported that the prevalence of neuropathic pain was $7 \%$ [2], while $4 \%$ of responders had chronic pain secondary to nerve disease and $10 \%$ were being treated by neurologists or neurosurgeons [3]. We believe that the 2012 analytic review by Smith and Torrance [4]which also includes data from the US-provides the most realistic estimate: $6-8 \%$, a proportion that is likely to increase in the future [5].

Neuropathic pain is a chronic condition and represents a significant burden for patients and healthcare systems. The quality of life is worse in patients with neuropathic pain than in those with other types of chronic pain [4]. Although the costs to healthcare systems are difficult to calculate, as they are fragmented based on the

Enhanced content To view enhanced content for this supplement go to http://www.medengine.com/Redeem/ 20DCF060253B492B.

G. Cruccu $(\square) \cdot$ A. Truini

Department of Neurology and Psychiatry, Sapienza

University, Rome, Italy

e-mail: giorgio.cruccu@uniroma1.it underlying disease, the overall expenditure on neuropathic pain is likely very high. Furthermore, neuropathic pain leads to psychosocial and emotional disorders that increase the burden on society [6].

The magnitude of the problem has been understood by both investigators and the pharmaceutical industry. A search of the PubMed database for the string "neuropathic pain" in the field Title/Abstract yielded 1020 articles published from inception to 1999 and 14,727 articles from 2000 to August 2017. Even more importantly, the number of clinical trials of drugs for the treatment of neuropathic pain increased from 104 to 892, indicating that a great amount of effort has been devoted to dealing with this problem.

Despite this attention, management of neuropathic pain continues to be a challenge [7]. Indeed, less than $50 \%$ of patients achieve pain relief of at least $50 \%$ with any drug or combination of drugs, whether old or new [8]. The current estimates, in fact, are well below that number [9]. Why is this so? Although the possible answers are many, the explanation that we favor most is that there are multiple pathophysiological mechanisms of neuropathic pain, whereas most drugs have a mechanism of action that addresses only one pain mechanism. One patient may often suffer from different types of neuropathic pain, and no one drug can effectively relieve all types of pain. 
This view has prompted investigators to try, through a careful assessment of the so-called sensory profiles, to identify the underlying pain mechanisms, and thus provide a more targeted treatment $[7,9,10]$. The need for this implies that the standard guidelines on neuropathic pain treatment, which are based on clinical trials that assess drug efficacy in patients who are enrolled because they are affected by a particular disease rather than a type of pain, necessarily fail to adequately address the problem.

Another research direction that holds significant promise in the field of neuropathic pain treatment is the use of combination therapies. By addressing different pathophysiological mechanisms, combination therapies can help patients achieve better pain relief than that provided by single-drug therapies [11]. Already widely used in routine practice, some combination therapies have now been included in clinical practice guidelines [12].

In this special issue of Pain and Therapy, a group of authors from the Neuropathic Pain Special Interest Group of the Italian Society of Neurology (Italian NeuPSIG) consider the problems associated with neuropathic pain, including pathophysiological mechanisms and pharmacology, the limitations of guidelines in clinical practice, and the apparently inescapable vicious circle of neuropathic pain and emotional and sleep disorders, where one disorder seems to reinforce the other.

\section{ACKNOWLEDGEMENTS}

This supplement has been sponsored by Pfizer, Italy. The article processing charges for this publication were also funded by Pfizer, Italy. Giorgio Cruccu and Andrea Truini thank Georgii Filatov of Springer Healthcare Communications who provided English language editing of the text. This medical writing assistance was funded by Pfizer, Italy. The named authors meet the International Committee of Medical Journal Editors (ICMJE) criteria for authorship for this manuscript, take responsibility for the integrity of the work as a whole, and have given final approval to the version to be published.
Disclosures. Giorgio Cruccu has received honorarium from Pfizer, as well as research grant, consulting fees and/or payments for lectures from Alfasigma Group, Angelini, Biogen, and Mundipharma. Andrea Truini has received honorarium from Pfizer, as well as research grant, consulting fees and/or payments for lectures from Alfasigma Group, Angelini, and Gruenenthal.

Compliance with Ethics Guidelines. This article is based on previously conducted studies and does not involve any new studies of human or animal subjects performed by any of the authors.

Data Availability. Data sharing is not applicable to this article as no datasets were generated or analyzed during the current study.

Open Access. This article is distributed under the terms of the Creative Commons Attribution-NonCommercial 4.0 International License (http://creativecommons.org/licenses/ by-nc/4.0/), which permits any noncommercial use, distribution, and reproduction in any medium, provided you give appropriate credit to the original author(s) and the source, provide a link to the Creative Commons license, and indicate if changes were made.

\section{REFERENCES}

1. van Hecke O, Austin SK, Khan RA, et al. Neuropathic pain in the general population: a systematic review of epidemiological studies. Pain. 2014;155:654-62. https://doi.org/10.1016/j.pain. 2013.11.013.

2. Bouhassira D, Lanteri-Minet $\mathrm{M}$, Attal $\mathrm{N}$, et al. Prevalence of chronic pain with neuropathic characteristics in the general population. Pain. 2008;136:380-7. https://doi.org/10.1016/j.pain. 2007.08.013.

3. Breivik H, Collett B, Ventafridda V, et al. Survey of chronic pain in Europe: prevalence, impact on daily life, and treatment. Eur J Pain. 2006;10:287-333. https://doi.org/10.1016/j.ejpain.2005.06.009.

4. Smith BH, Torrance N. Epidemiology of neuropathic pain and its impact on quality of life. Curr 
Pain Headache Rep. 2012;16:191-8. https://doi.org/ 10.1007/s11916-012-0256-0.

5. Moulin D, Boulanger A, Clark AJ, et al. Pharmacological management of chronic neuropathic pain: revised consensus statement from the Canadian Pain Society. Pain Res Manag. 2014;19:328-35.

6. Dworkin RH, Panarites CJ, Armstrong EP, et al. Healthcare utilization in people with postherpetic neuralgia and painful diabetic peripheral neuropathy. J Am Geriatr Soc. 2011;59:827-36. https://doi. org/10.1111/j.1532-5415.2011.03403.x.

7. Baron R, Maier C, Attal N, et al. Peripheral neuropathic pain: a mechanism-related organizing principle based on sensory profiles. Pain. 2017;158: 261-72. https://doi.org/10.1097/j.pain.000000000 0000753 .

8. Hansson PT, Attal N, Baron R, et al. Toward a definition of pharmacoresistant neuropathic pain. Eur J Pain. 2009;13:439-40. https://doi.org/10.1016/j. ejpain.2009.02.008.
9. Neuropathy Eisenstein M. A name for their pain. Nature. 2016;535:S10-1. https://doi.org/10.1038/ 535S10a.

10. Truini A, Garcia-Larrea L, Cruccu G. Reappraising neuropathic pain in humans-how symptoms help disclose mechanisms. Nat Rev Neurol. 2013;9:572-82. https://doi.org/10.1038/nrneurol. 2013.180.

11. Gilron I, Jensen TS, Dickenson AH. Combination pharmacotherapy for management of chronic pain: from bench to bedside. Lancet Neurol. 2013;12:1084-95. https://doi.org/10.1016/S14744422(13)70193-5.

12. Holbech JV, Jung A, Jonsson T, et al. Combination treatment of neuropathic pain: Danish expert recommendations based on a Delphi process. J Pain Res. 2017;10:1467-75. https://doi.org/10.2147/JPR. S138099. 